\title{
L D B: Atuação e Formação do Psicólogo Escolar
}

Guzzo, R. S. L. (Org.) (1999). Psicologia Escolar: LDB e Educação Hoje. Campinas - SP: Alínea, 144 pp. ISBN 85-86491-28-4.

Desde sua promulgação em 1996, a LDB (Lei de Diretrizes e Bases) - Lei nº 9394/96, tem sido tema amplamente discutido em todas as áreas envolvidas com educação e foi foco especial de um grupo de estudiosos pertencentes à Associação Nacional de Pesquisa e Pós-graduação que se propôs a discutir as contribuições da Psicologia à Educação.

A livro aqui resenhado oferece uma colaboração significativa aos profissionais da área e interessados no assunto, mostrando conseqüências, necessidades e perspectivas diante da nova conjuntura com a implantação dessa Lei.

A organizadora, Dr ${ }^{a}$ Raquel Souza Lobo Guzzo, é professora titular do Instituto de Psicologia da Pontifícia Universidade Católica de Campinas, Doutora em Psicologia Escolar pela Universidade de São Paulo e pesquisadora credenciada pelo CNPq.

Nas páginas iniciais faz a apresentação do livro e das autoras colaboradoras:

$\operatorname{Dr}^{\mathrm{a}}$ Maria Helena Novaes (Pontifícia Universidade Católica do Rio de Janeiro); Dr $^{\mathrm{a}}$ Geraldina Porto Witter (Pontifícia Universidade Católica de Campinas/SP); Dra Zilda Del Prette (Universidade Federal de São Carlos/ SP); Dr ${ }^{\mathrm{a}}$ Vera Trindade Gomes (Universidade do Estado do Rio de Janeiro); Dr ${ }^{a}$ Sandra Francesca Conte de Almeida (Universidade de Brasília) e $\mathrm{Dr}^{\mathrm{a}}$ Ana Maria Torezan (Pontifícia Universidade Católica de Campinas/SP).

A Capítulo I é reservado à pesquisa sobre Psicologia, Educação e LDB da Dr ${ }^{\mathrm{a}}$ Del Prette, enfocando a importância do conhecimento do conteúdo da LDB por educadores e os que trabalham na interface Psicologia-Educação. Faz uma análise detalhada de alguns artigos da Lei mostrando as contradições existentes no que se refere à atuação do psicólogo em termos educacionais. Reconhece o mérito do texto em excluir muitas despesas indevidamente consideradas como recursos financeiros para a educação, porém a exclusão dos serviços psicológicos torna-se estranha quando se considera a importância da Psicologia como um dos fundamentos da Educação.

Segue a autora apresentando uma análise realística das condições em que, há muito, vem atuando o psicólogo que trabalha com questões educacionais no Brasil, de um lado tem-se docentes pesquisadores das universidades; de outro os profissionais liberais, graduados em Psicologia. Del Prette, de forma muito habilidosa, apresenta o Psicólogo, que além de cidadão intelectual, precisa participar dos movimentos em defesa da educação pública e de qualidade e, no caso específico da LDB, estar atento não apenas ao seu conteúdo, mas também às suas possíveis distorções conjunturais. Ao terminar seu artigo deixa um parágrafo sem fechamento, ficando assim prejudicada a compreensão.

Torezan, a segunda colaboradora, traz em "Psicologia escolar e a nova conjuntura educacional brasileira", uma visão do compromisso assumido por vários países, dentre eles o Brasil, de "Educação para todos", inclusive aos portadores de deficiência, preferencialmente na rede regular de ensino. A autora analisa vários artigos e indica que é preciso considerar, no entanto, que apesar dos aspectos ambíguos, a LDB coloca ênfase na integração da pessoa deficiente no ensino regular e apresenta outros pontos que indicam avanços, como o estabelecimento de relações mais estreitas entre ensino regular e especial, a ampliação do poder público, a oferta da Educação 
Especial durante a educação infantil. Neste Capítulo, Torezan ainda cita vários autores que escrevem sobre deficiência como sendo um fenômeno mais relacionado ao mundo social do que propriamente à dimensão biológica. O "não aprender" do aluno se deve a problemas intrínsecos e que, só os profissionais da área da saúde como psicólogos, médicos etc. é que poderão resolvê-los. Para a autora, buscar novas formas de ação junto à escola se faz necessário, direcionando o foco da atenção para as múltiplas e complexas questões relativas ao processo ensino-aprendizagem.

A formação do psicólogo escolar e os impasses entre a teoria e a prática são apresentados, no Capítulo seguinte, por Trindade Gomes, que diante da complexidade da Psicologia para a Educação no que se refere à distância entre enfoque teÓrico e suas implicações práticas, se propôs a caracterizar, em seu estudo, a atuação profissional do psicólogo na área da educação escolar, assim como a sua formação acadêmica, visando contribuir para a construção teórica do perfil da ação do psicólogo em nível normativo na escola brasileira, considerando para isso a referida ação como fator de compromisso com a transformação e desenvolvimento social. Cita vários autores que em suas pesquisas fazem referência à importância da Psicologia para a Educação, por ser esta um dos campos de atuação onde, por sua amplitude e complexidade, o psicólogo pode aplicar mais profunda e criativamente as teorias e técnicas da Psicologia. Salienta a autora que apesar do desenvolvimento que a Psicologia Escolar vem passando, ainda há um árduo e longo caminho a percorrer para que o psicólogo escolar ocupe um espaço significativo no panorama educacional.

No quarto Capítulo, Almeida mostra o psicólogo no cotidiano da escola: re-significando a atuação profissional. Salienta que determinados profissionais dessa área não agem adequadamente por não terem clareza e lucidez suficientes sobre os determinantes filosófico ideológicos de determinadas teorias psicológicas. Estas ações, segundo a autora se devem às dissociações freqüentes entre teoria e prática não atingindo, dessa forma, as finalidades e os objetivos da ação e intervenção do psicólogo na escola. Faz várias considerações procurando resgatar a identidade do psicólogo (que perdeu espaço para o psicopedagogo) na escola, de modo que as diferenças profissionais sejam respeitadas e afirmadas, com base no desenvolvimento de competências técnicas e pessoais, específicas da Psicologia, e na conscientização de papéis, responsabilidades e funções. Aponta a re-significação da atuação do profissional, em Psicologia, para o contexto escolar como necessária, pois o psicólogo é um aliado constante da Pedagogia.

É no Capítulo cinco que Novaes enfoca o tema inovação trazida pela tecnologia dos meios de comunicação, informação e difusão do conhecimento que pode trazer efeitos nem sempre desejáveis para a convivência humana. Apresenta nítida sinalização desse cenário mostrando que na atualidade ele está desvinculado de uma sólida revisão dos valores humanos, não garantindo uma sociedade consciente, responsável e mais justa. Para enfrentar tais desafios a autora aponta novas formas de parcerias e relações institucionais para enfrentar tais desafios. Dessa forma, o psicólogo escolar deve ser um profissional em constante movimento, sempre procurando se reciclar e aperfeiçoar seus conhecimentos, revendo e analisando suas práticas, aliado constante da transformação social e dos interesses da maioria da população.

Psicólogo escolar no ensino superior e a Lei de Diretrizes e Bases é o tema do sexto Capítulo, de Witter. Ressalta que determinadas mudanças podem ocorrer sem a intervenção da lei e outras que só se viabilizam pela lei, como o caso do Ensino Superior e, por conseqüência, a relação psicólogo escolar e Ensino Superior. Analisa as possibilidades de atuação do Psicólogo Escolar no campo universitário como profissional e docente, diante dos vários artigos que a LDB estipula em 
relação ao ensino superior. Indica que a formação do psicólogo escolar, como dos demais, deve ser marcada pela interdisciplinaridade, sem descaracterizar a ênfase no psicológico, e multiteórica, transteórica ou de unicidade em busca da melhor solução para cada situação. A autora aponta na LDB possibilidades implícitas de atuação do psicólogo escolar e, enfatiza a necessidade deste psicólogo escolar além de suas funções, atualizações e cursos de pós-graduação, estar sempre engajado com pesquisa, a qual deve ter destaque em sua formação para ser um bom profissional pesquisador.

No sétimo e último Capítulo, Guzzo apresenta uma análise da falácia do sistema educacional brasileiro em todos os níveis. Salienta que tanto a escola pública quanto a particular não dispõem de uma equipe técnica de apoio ao professor, no que diz respeito ao acompanhamento e desenvolvimento integral dos estudante, fato este que não ocorre em países mais desenvolvidos educacionalmente. Porém, aponta que investimentos em diferentes áreas de atuação e formação profissional em Psicologia Escolar têm sido feitos com o intuito de buscar um modelo de atuação para este profissional e que corresponda às necessidades do sistema educacional brasileiro.

Acompanhando cada artigo o leitor pode encontrar as referências bibliográficas utilizadas, atuais e adequadas, permitindo esclarecimentos e aprofundamento nos temas.

O livro é bem organizado, respeitando em sua articulação uma seqüência temática que estabelece continuidade de interesse ao leitor.

A linguagem, de maneira geral, é objetiva facilitando a compreensão e a reflexão geradas pela comunicação do conhecimento e da experiência das autoras.

A leitura deste livro é recomendada a todos os profissionais e estudiosos da Educação e, em especial, em Psicologia Escolar que encontrarão nele contribuição significante que os levarão a repensar a realidade brasileira em termos de LDB.

Elza Maria Tavares Silva

Universidade de Mogi das Cruzes

Recebido em abril 1999.

Encaminhado para revisores em maio 1999.

Aprovado em maio 1999. 